\title{
A Hybrid-Input Negative Ring-type Converter Using Clean Energy Power Supplies
}

\author{
Kei Eguchi $^{1 *}$, Ichirou Oota ${ }^{2}$, Shinya Terada ${ }^{2}$, Hongbing Zhu ${ }^{3}$ \\ ${ }^{1}$ Fukuoka Institute of Technology, \\ 3-30-1 Wajiro-Higashi, Higashi-Ku, Fukuoka 811-0295, Japan \\ ${ }^{2}$ Kumamoto National College of Technology, \\ 2659-2, Suya, Koushi, Kumamoto, 861-1102, Japan \\ ${ }^{3}$ Hiroshima Kokusai Gakuin University, \\ 6-20-1 Nakano Aki-ku, Hiroshima 739-0321, Japan \\ * Corresponding author's Email: eguti@ fit.ac.jp
}

\begin{abstract}
For back-lighting applications, a white LED (WLED) driver using a hybrid-input negative ring-type converter is proposed in this paper. To drive the LED's cathode, the proposed driver offers the negative steppedup/stepped-down voltages by converting clean energy. The proposed driver can realize longer battery lifetime than conventional converters, because 1. In spite of the variation in clean energy input, the proposed step-up/step-down driver can utilize the clean energy effectively and 2 . The proposed driver can charge a rechargeable battery when the back-light is standby mode. The properties of the proposed driver were clarified by theoretical analyses and SPICE simulations. SPICE simulations showed that the proposed driver can provide the sufficient voltage to drive LEDs by using not only battery energy but also clean energy. Furthermore, the theoretical formulas are useful for designing the proposed driver, because the theoretical results corresponded well with the simulation results.
\end{abstract}

Keywords: Power converters; DC-DC converters; Switched-capacitor circuits; Step-up/step-down converters; WLED

\section{Introduction}

In portable electronics, a white LED (WLED) is one of the most promising device for display back-lighting. As a driver circuit of WLEDs for display back-lighting, capacitor-based DC-DC converters [1]-[13] have been used, because the capacitor-based converter can realize thin circuit composition, light-weight, no flux of magnetic induction, and so on. By converting the battery voltage which is $3 \sim 4.2 \mathrm{~V}$ (Typ. $=3.7 \mathrm{~V}$ ), the switching converter offers $3.5 \sim 3.8 \mathrm{~V}$ to drive WLEDs at up to $20 \mathrm{~mA}$.

In the conventional converter such as the $2 \times / 1.5 \times$ charge-pump [1]-[7], the positive stepped-up voltage is generated to drive the LED's anodes. However, when the LEDs are mismatched, the converter must switch to step-up mode due to the bad forward voltage of only one LED. To overcome this weak point, the $-0.5 \times$ charge-pump driver has been proposed [8]. By using the individual mode switching, the $-0.5 \times$ charge-pump drives only the highest LED with the bad forward voltage. Therefore, the $-0.5 \times$ driver can alleviate energy loss more than the $2 \times / 1.5 \times$ driver. However, the conversion ratio of the $-0.5 \times$ chargepump is predetermined by circuit structure. Therefore, the energy loss caused by output regulation becomes large when output $V_{\text {out }}$ is $V_{\text {out }} \gg 3.5 \sim$ 


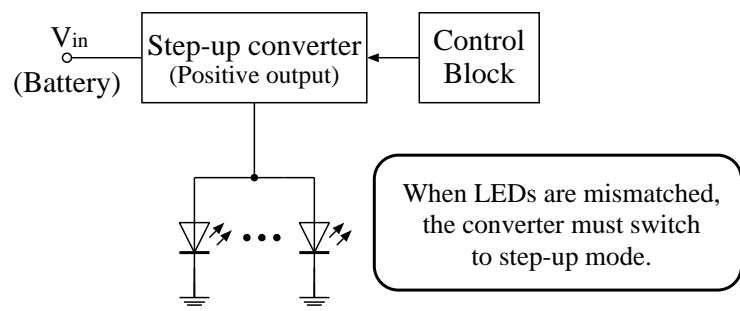

(a)

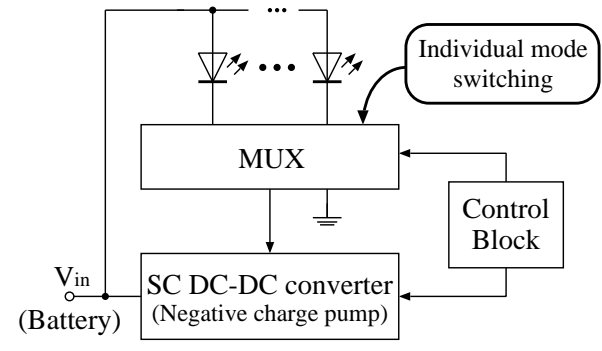

(b)

Figure 1 Block diagram of conventional drivers, (a) $2 \times / 1.5 \times$ charge-pump driver, (b) $-0.5 \times$ charge-pump driver

\section{$3.8 \mathrm{~V}^{1}$.}

In this paper, a WLED driver using a hybrid-input negative ring-type converter [9]-[11] is proposed. To drive the LED's cathode, the proposed driver offers the negative voltages by converting clean energy, though the conventional ring-type converters [9]-[11] cannot provide the negative voltage. Unlike conventional drivers [1]-[11], the proposed driver realizes stepped-up/steppeddown conversion according to the voltage of clean energy source. Therefore, the proposed driver can alleviate energy loss more than conventional drivers. Furthermore, the proposed driver can charge a rechargeable battery when the back-light is standby mode. Consequently, the proposed driver can realize long battery lifetime.

Concerning the proposed driver, theoretical analyses and SPICE simulations are performed to confirm the validity of circuit design.

\section{Circuit Structure}

\subsection{Conventional Driver}

Figure 1 shows the block diagram of the conventional drivers. In Figure 1 (a), the positive stepped-up voltage is generated to drive the LED's anodes by using the $2 \times / 1.5 \times$ charge-pump [1]-[7]. Thus, when the LEDs are mismatched, the converter must switch to step-up mode due to the bad forward voltage of only

\footnotetext{
${ }^{1}$ The target voltage to drive WLEDs is $3.5 \sim 3.8 \mathrm{~V}$.
}

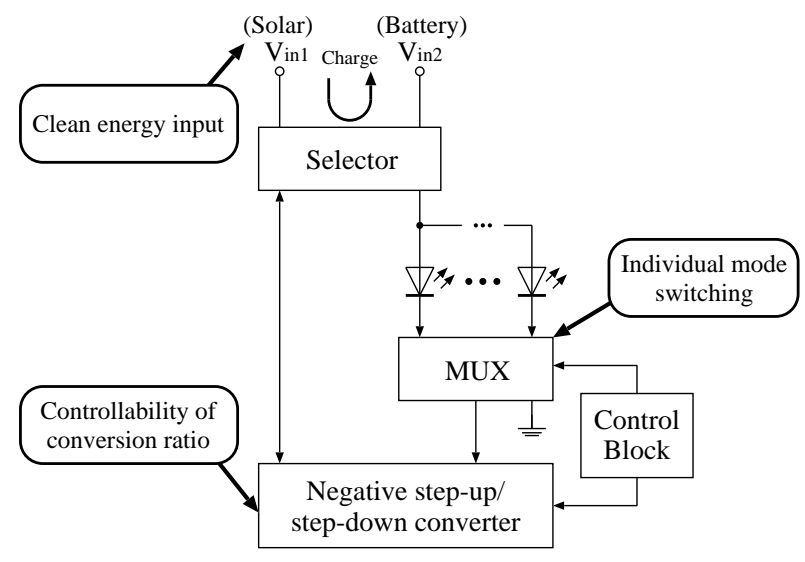

Figure 2 Block diagram of the proposed driver

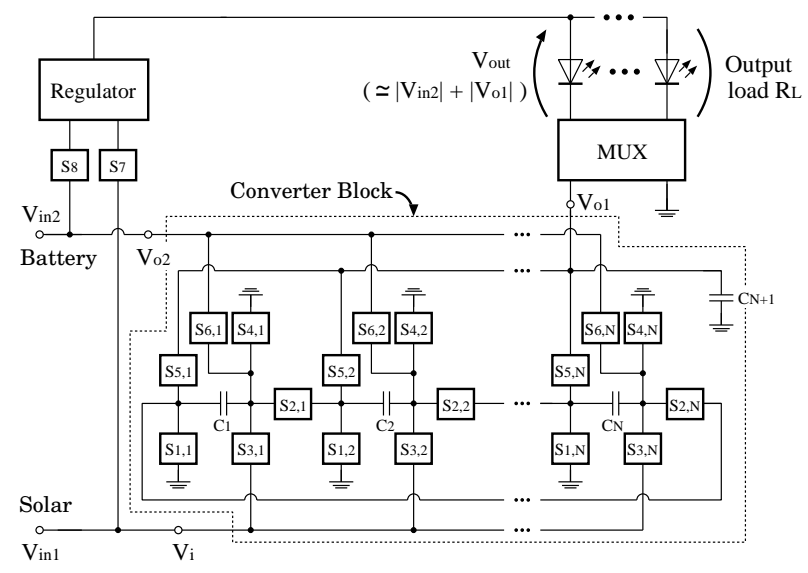

Figure 3 An example of the proposed driver with 3-stages

one LED. Consequently, the conventional approach shown in Figure 1 (a) is difficult to achieve high power efficiency.

To overcome this problem, the LED driver shown in Figure 1 (b) [8] has been proposed. In Figure 1 (b), the negative stepped-down voltage is generated to drive the LED's cathode only when the input voltage is insufficient to drive $1 \times$ transfer mode. Therefore, the $-0.5 \times$ charge-pump driver can realize high power efficiency. This technique is called the individual mode switching. However, the conventional approach shown in Figure 1 (b) is difficult to improve power efficiency further, because the conversion ratio of the negative charge-pump is fixed to $-0.5 \times$ stepdown.

\subsection{Proposed Converter}

Figure 2 shows the block diagram of the proposed driver. The proposed driver consists of a negative stepup/step-down converter, a selector and a multiplexer. 
Table 1 Comparison of circuit characteristics

\begin{tabular}{|c|c|c|c|c|}
\hline & \multicolumn{2}{|c|}{$\begin{array}{c}\text { Approach-1 } \\
\text { using step-up converters }\end{array}$} & \multirow{2}{*}{$\begin{array}{l}\text { Approach-2 } \\
\text { using negative } \\
\text { charge-pumps }\end{array}$} & \multirow{2}{*}{$\begin{array}{c}\text { Proposed } \\
\text { driver }\end{array}$} \\
\hline & Inductor-based & Capacitor-based & & \\
\hline $\begin{array}{l}\text { Individual mode } \\
\text { switching }\end{array}$ & NG & NG & $\mathrm{OK}$ & OK \\
\hline $\begin{array}{l}\text { Controllability of } \\
\text { conversion ratio }\end{array}$ & OK & NG & $\mathrm{NG}$ & $\mathrm{OK}$ \\
\hline $\begin{array}{l}\text { Recharge-ability } \\
\text { of battery }\end{array}$ & NG & NG & NG & OK \\
\hline $\begin{array}{c}\text { No flux of } \\
\text { magnetic induction }\end{array}$ & NG & $\mathrm{OK}$ & $\mathrm{OK}$ & OK \\
\hline $\begin{array}{c}\text { Simplicity of } \\
\text { circuit structure }\end{array}$ & $\mathrm{OK}$ & NG & NG & NG \\
\hline
\end{tabular}

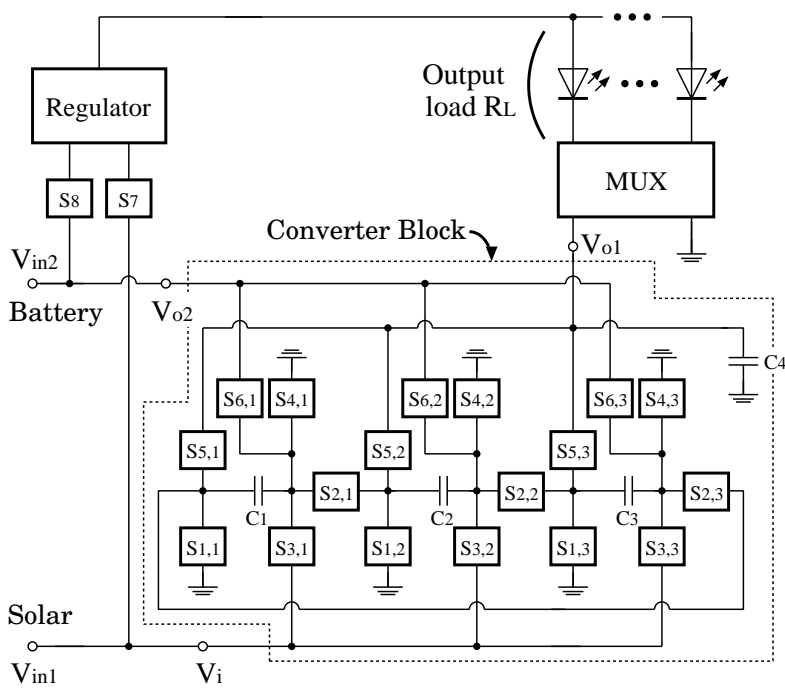

Figure 4 An example of the proposed driver with 3-stages

Table 1 is the comparison between the proposed driver and the conventional driver. As Table 1 shows, the proposed driver has the following features: 1. By using individual mode switching, the proposed converter drives the LED's anode when clean enrgy input $V_{i n 1}$ is sufficient to turn on LEDs. On the other hand, when $V_{i n 1}$ is insufficient, the anode and the cathode of LEDs are driven by using $V_{i n 2}$ and $V_{i n 1}$, respectively. Consequently, the proposed driver can alleviate the power consumption of the battery. 2. Unlike the negative charge-pump, the output voltage of the proposed driver can be adjusted by controlling the duty factor of clock pulses. Therefore, the proposed driver can achieve high power efficiency, because the nega- tive step-up/step-down converter can utilize the clean energy effectively. 3. By converting clean energy, the proposed driver can charge a rechargeable battery when the LED back-light is standby mode. Therefore, the proposed driver achieves long battery lifetime.

Figure 3 shows the general form of the proposed driver. In spite of the voltage change in clean energy input $V_{i n 1}$, the proposed driver offers output voltage $V_{\text {out }}$ by using the negative step-up/step-down converter. Concretely, in the simple example of the proposed driver shown in Figure 4, the converter block changes the operation modes as shown in Table 2. In Table 2, the timing of power switches in the converter block is set to as shown in Table 3. As Tables 2 and 3 show, the converter block provides the negative stepped-up/stepped-down voltage and the positive stepped-up voltage in the case of Mode-1 $\sim 7$ and Mode-8 10, respectively.

In the next section, the properties of the proposed driver will be analyzed theoretically.

\section{Theoretical Analysis}

\subsection{Analysis of Mode-3}

For easy understanding, let us consider the properties of the proposed driver shown in Figure 4. To save space, the theoretical analysis in the case of Mode-3 and Mode- 5 is discussed, though the proposed driver of Figure 4 can offer ten types of output voltages.

First, the equivalent circuit of the converter block is derived under conditions where 1. Parasitic elements are negligibly small and 2. Time constant is much larger than the period of clock pulses. Figure 
Table 2 Setting of conversion ratio

\begin{tabular}{|c|c|c|c|c|}
\hline & LED & Range of Input voltage $V_{i n 1}$ & Conversion Ratio & Output Voltage \\
\hline Mode-1 & On & $3\left(V_{t a g}-V_{i n 2}\right)<V_{i n 1}$ & $-\frac{1}{3} \times$ & $V_{\text {out }}=V_{\text {in } 2}+\frac{1}{3} V_{\text {in } 1}$ \\
\hline Mode-2 & On & $2\left(V_{t a g}-V_{i n 2}\right)<V_{i n 1} \leq 3\left(V_{t a g}-V_{i n 2}\right)$ & $-\frac{1}{2} \times$ & $V_{\text {out }}=V_{\text {in } 2}+\frac{1}{2} V_{\text {in } 1}$ \\
\hline Mode-3 & On & $\frac{3}{2}\left(V_{t a g}-V_{i n 2}\right)<V_{i n 1} \leq 2\left(V_{t a g}-V_{i n 2}\right)$ & $-\frac{2}{3} \times$ & $V_{\text {out }}=V_{\text {in } 2}+\frac{2}{3} V_{\text {in } 1}$ \\
\hline Mode-4 & On & $V_{t a g}-V_{i n 2}<V_{i n 1} \leq \frac{3}{2}\left(V_{t a g}-V_{i n 2}\right)$ & $-1 \times$ & $V_{\text {out }}=V_{\text {in } 2}+V_{\text {in } 1}$ \\
\hline Mode-5 & On & $\frac{2}{3}\left(V_{t a g}-V_{i n 2}\right)<V_{i n 1} \leq V_{t a g}-V_{i n 2}$ & $-\frac{3}{2} \times$ & $V_{\text {out }}=V_{\text {in } 2}+\frac{3}{2} V_{\text {in } 1}$ \\
\hline Mode-6 & On & $\frac{1}{2}\left(V_{t a g}-V_{i n 2}\right)<V_{i n 1} \leq \frac{2}{3}\left(V_{t a g}-V_{i n 2}\right)$ & $-2 \times$ & $V_{\text {out }}=V_{\text {in } 2}+2 V_{i n 1}$ \\
\hline Mode-7 & On & $\frac{1}{3}\left(V_{t a g}-V_{i n 2}\right)<V_{i n 1} \leq \frac{1}{2}\left(V_{t a g}-V_{i n 2}\right)$ & $-3 \times$ & $V_{\text {out }}=V_{\text {in } 2}+3 V_{\text {in } 1}$ \\
\hline Mode-8 & Off & $\frac{2}{3} V_{t a g}<V_{i n 1}$ & $\frac{3}{2} \times$ & $V_{o 2}=\frac{3}{2} V_{i n 1}$ \\
\hline Mode-9 & Off & $\frac{1}{2} V_{t a g}<V_{i n 1} \leq \frac{2}{3} V_{t a g}$ & $2 \times$ & $V_{o 2}=2 V_{i n 1}$ \\
\hline Mode-10 & Off & $\frac{1}{3} V_{t a g}<V_{i n 1} \leq \frac{1}{2} V_{t a g}$ & $3 \times$ & $V_{o 2}=3 V_{i n 1}$ \\
\hline
\end{tabular}

$V_{t a g} \cdots$ Target output voltage

5 shows instantaneous equivalent circuits of the proposed driver. In Figure 5, $R_{o n}{ }^{2}$ denotes the on-resistance of power switches. In the steady state of Figure 5, the differential value of electric charges in $C_{k}(k=$ $\{1, \ldots, 4\})$ satisfies

$$
\sum_{t=T 1}^{T 6} \Delta q_{t}^{k}=0,
$$

where $\Delta q_{T 1}^{k}, \cdots, \Delta q_{T 6}^{k}$ denote electric charges when State $-T 1, \cdots, T 6$, respectively.

In the case of charging phase (see Figs.5 (a), (c) and (e)), differential values of electric charges in input terminal $v_{i}$ and output terminal $v_{o 1}, \Delta q_{T 1, V_{i}}, \Delta q_{T 3, V_{i}}$, $\Delta q_{T 5, V_{i}}, \Delta q_{T 1, V_{o 1}}, \Delta q_{T 3, V_{o 1}}$ and $\Delta q_{T 5, V_{o 1}}$, are given by

$$
\begin{aligned}
& \Delta q_{T 1, V_{i}}=\Delta q_{T 1}^{1}, \quad \Delta q_{T 1, V_{o 1}}=\Delta q_{T 1}^{4}, \\
& \Delta q_{T 3, V_{i}}=\Delta q_{T 3}^{2}, \quad \Delta q_{T 3, V_{o 1}}=\Delta q_{T 3}^{4}, \\
& \text { and } \quad \Delta q_{T 5, V_{i}}=\Delta q_{T 5}^{3}, \quad \Delta q_{T 5, V_{o 1}}=\Delta q_{T 5}^{4} \text {, }
\end{aligned}
$$

where the following conditions are satisfied:

$$
\Delta q_{T 1}^{1}=\Delta q_{T 1}^{2}=\Delta q_{T 1}^{3},
$$

\footnotetext{
${ }^{2}$ The SC power converters are known as an implementable converter, because no magnetic component is required. In the LED driver implemented into a chip, the direction of fluctuation in on-resistances is almost the same. Therefore, to simplify the theoretical analysis, we assume that all the power switches have the same on-resistances.
}

$$
\begin{aligned}
& \Delta q_{T 3}^{1}=\Delta q_{T 3}^{2}=\Delta q_{T 3}^{3} \\
& \text { and } \quad \Delta q_{T 5}^{1}=\Delta q_{T 5}^{2}=\Delta q_{T 5}^{3} \text {. }
\end{aligned}
$$

In the case of transfer phase (see Figs.5 (b), (d) and (f)), differential values of electric charges in input terminal $v_{i}$ and output terminal $v_{o 1}, \Delta q_{T 2, V_{i}}, \Delta q_{T 4, V_{i}}$, $\Delta q_{T 6, V_{i}}, \Delta q_{T 2, V_{o 1}}, \Delta q_{T 4, V_{o 1}}$ and $\Delta q_{T 6, V_{o 1}}$, are given by

$$
\begin{aligned}
\Delta q_{T 2, V_{i}} & =0, \Delta q_{T 2, V_{o 1}}=-\Delta q_{T 2}^{1}+\Delta q_{T 2}^{4}, \\
\Delta q_{T 4, V_{i}} & =0, \Delta q_{T 4, V_{o 1}}=-\Delta q_{T 4}^{2}+\Delta q_{T 4}^{4}, \\
\text { and } \Delta q_{T 6, V_{i}} & =0, \Delta q_{T 6, V_{o 1}}=-\Delta q_{T 6}^{3}+\Delta q_{T 6}^{4},
\end{aligned}
$$

where the following conditions are satisfied:

$$
\begin{array}{rlrl}
\Delta q_{T 2}^{1} & =\Delta q_{T 2}^{2}, & \Delta q_{T 2}^{3}=0, \\
\Delta q_{T 4}^{2} & =\Delta q_{T 4}^{3}, & \Delta q_{T 4}^{1}=0, \\
\text { and } \quad \Delta q_{T 6}^{3}=\Delta q_{T 6}^{1}, & \Delta q_{T 6}^{2}=0 .
\end{array}
$$

By using Eqs.(2) (5), averaged input current $\overline{I_{i}}$ and averaged output current $\overline{I_{o 1}}$ are given by

$$
\begin{aligned}
\overline{I_{i}} & =\sum_{t=T 1}^{T 6} \Delta q_{t, V_{i}} / T:=\Delta q_{V_{i}} / T \\
\text { and } \overline{I_{o 1}} & =\sum_{t=T 1}^{T 6} \Delta q_{t, V_{o 1}} / T:=\Delta q_{V_{o 1}} / T
\end{aligned}
$$


Table 3 Setting of clock pulses in the converter block

\begin{tabular}{|c|c|c|c|c|}
\hline & Charging phase & On & Transfer phase & On \\
\hline \multirow{3}{*}{$\begin{array}{l}\text { Mode-1 } \\
(-1 / 3 \times)\end{array}$} & $\begin{array}{l}\mathrm{T} 1 \\
\end{array}$ & $\bar{S}_{1,1}, S_{2,1}, S_{2,2}, S_{3,3}$ & T2 & 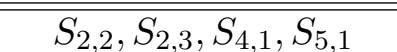 \\
\hline & T3 & $S_{1,2}, S_{2,2}, S_{2,3}, S_{3,1}$ & $\mathrm{~T} 4$ & $S_{2,1}, S_{2,3}, S_{4,2}, S_{5,2}$ \\
\hline & T5 & $S_{1,3}, S_{2,1}, S_{2,3}, S_{3,2}$ & T6 & $S_{2,1}, S_{2,2}, S_{4,3}, S_{5,3}$ \\
\hline \multirow{3}{*}{$\begin{array}{c}\text { Mode-2 } \\
(-1 / 2 \times)\end{array}$} & $\mathrm{T} 1$ & $S_{1,1}, S_{2,1}, S_{2,2}, S_{3,2}$ & $\mathrm{~T} 2$ & $S_{2,2}, S_{2,3}, S_{4,1}, S_{5,1}$ \\
\hline & T3 & $S_{1,2}, S_{2,2}, S_{2,3}, S_{3,3}$ & $\mathrm{~T} 4$ & $S_{2,1}, S_{2,3}, S_{4,2}, S_{5,2}$ \\
\hline & T5 & $S_{1,3}, S_{2,1}, S_{2,3}, S_{3,1}$ & T6 & $S_{2,1}, S_{2,2}, S_{4,3}, S_{5,3}$ \\
\hline \multirow{3}{*}{$\begin{array}{l}\text { Mode-3 } \\
(-2 / 3 \times)\end{array}$} & $\mathrm{T} 1$ & $S_{1,1}, S_{2,1}, S_{2,2}, S_{3,3}$ & $\mathrm{~T} 2$ & $S_{2,2}, S_{2,3}, S_{4,1}, S_{5,3}$ \\
\hline & T3 & $S_{1,2}, S_{2,2}, S_{2,3}, S_{3,1}$ & $\mathrm{~T} 4$ & $S_{2,1}, S_{2,3}, S_{4,2}, S_{5,1}$ \\
\hline & T5 & $S_{1,3}, S_{2,1}, S_{2,3}, S_{3,2}$ & T6 & $S_{2,1}, S_{2,2}, S_{4,3}, S_{5,2}$ \\
\hline \multirow{3}{*}{$\begin{array}{c}\text { Mode-4 } \\
(-1 \times)\end{array}$} & $\mathrm{T} 1$ & $S_{1,1}, S_{2,1}, S_{2,2}, S_{3,1}$ & $\mathrm{~T} 2$ & $S_{2,2}, S_{2,3}, S_{4,1}, S_{5,1}$ \\
\hline & $\mathrm{T} 3$ & $S_{1,2}, S_{2,2}, S_{2,3}, S_{3,2}$ & $\mathrm{~T} 4$ & $S_{2,1}, S_{2,3}, S_{4,2}, S_{5,2}$ \\
\hline & T5 & $S_{1,3}, S_{2,1}, S_{2,3}, S_{3,3}$ & T6 & $S_{2,1}, S_{2,2}, S_{4,3}, S_{5,3}$ \\
\hline \multirow{3}{*}{$\begin{array}{l}\text { Mode-5 } \\
(-3 / 2 \times)\end{array}$} & $\mathrm{T} 1$ & $S_{1,1}, S_{2,1}, S_{2,2}, S_{3,2}$ & $\mathrm{~T} 2$ & $S_{2,2}, S_{2,3}, S_{4,1}, S_{5,2}$ \\
\hline & T3 & $S_{1,2}, S_{2,2}, S_{2,3}, S_{3,3}$ & $\mathrm{~T} 4$ & $S_{2,1}, S_{2,3}, S_{4,2}, S_{5,3}$ \\
\hline & T5 & $S_{1,3}, S_{2,1}, S_{2,3}, S_{3,1}$ & T6 & $S_{2,1}, S_{2,2}, S_{4,3}, S_{5,1}$ \\
\hline \multirow{3}{*}{$\begin{array}{l}\text { Mode-6 } \\
(-2 \times)\end{array}$} & $\mathrm{T} 1$ & $S_{1,1}, S_{2,1}, S_{2,2}, S_{3,1}$ & $\mathrm{~T} 2$ & $S_{2,2}, S_{2,3}, S_{4,1}, S_{5,3}$ \\
\hline & $\mathrm{T} 3$ & $S_{1,2}, S_{2,2}, S_{2,3}, S_{3,2}$ & $\mathrm{~T} 4$ & $S_{2,1}, S_{2,3}, S_{4,2}, S_{5,1}$ \\
\hline & T5 & $S_{1,3}, S_{2,1}, S_{2,3}, S_{3,3}$ & T6 & $S_{2,1}, S_{2,2}, S_{4,3}, S_{5,2}$ \\
\hline \multirow{3}{*}{$\begin{array}{l}\text { Mode-7 } \\
(-3 \times)\end{array}$} & $\mathrm{T} 1$ & $S_{1,1}, S_{2,1}, S_{2,2}, S_{3,1}$ & $\mathrm{~T} 2$ & $S_{2,2}, S_{2,3}, S_{4,1}, S_{5,2}$ \\
\hline & T3 & $S_{1,2}, S_{2,2}, S_{2,3}, S_{3,2}$ & $\mathrm{~T} 4$ & $S_{2,1}, S_{2,3}, S_{4,2}, S_{5,3}$ \\
\hline & T5 & $S_{1,3}, S_{2,1}, S_{2,3}, S_{3,3}$ & T6 & $S_{2,1}, S_{2,2}, S_{4,3}, S_{5,1}$ \\
\hline \multirow{3}{*}{$\begin{array}{c}\text { Mode- } 8 \\
(3 / 2 \times)\end{array}$} & T1 & $\bar{S}_{1,1}, S_{2,1}, S_{2,2}, S_{3,2}, S_{6,3}$ & T2 & 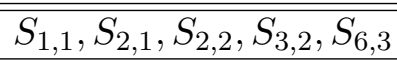 \\
\hline & T3 & $S_{1,2}, S_{2,2}, S_{2,3}, S_{3,3}, S_{6,1}$ & T4 & $S_{1,2}, S_{2,2}, S_{2,3}, S_{3,3}, S_{6,1}$ \\
\hline & T5 & $S_{1,3}, S_{2,1}, S_{2,3}, S_{3,1}, S_{6,2}$ & T6 & $S_{1,3}, S_{2,1}, S_{2,3}, S_{3,1}, S_{6,2}$ \\
\hline \multirow{3}{*}{$\begin{array}{c}\text { Mode-9 } \\
(2 \times)\end{array}$} & $\mathrm{T} 1$ & $S_{1,1}, S_{2,1}, S_{2,2}, S_{3,1}, S_{6,2}$ & $\mathrm{~T} 2$ & $S_{1,1}, S_{2,1}, S_{2,2}, S_{3,1}, S_{6,2}$ \\
\hline & $\mathrm{T} 3$ & $S_{1,2}, S_{2,2}, S_{2,3}, S_{3,2}, S_{6,3}$ & $\mathrm{~T} 4$ & $S_{1,2}, S_{2,2}, S_{2,3}, S_{3,2}, S_{6,3}$ \\
\hline & T5 & $S_{1,3}, S_{2,1}, S_{2,3}, S_{3,3}, S_{6,1}$ & T6 & $S_{1,3}, S_{2,1}, S_{2,3}, S_{3,3}, S_{6,1}$ \\
\hline \multirow{3}{*}{$\begin{array}{c}\text { Mode-10 } \\
(3 \times)\end{array}$} & $\mathrm{T} 1$ & $S_{1,1}, S_{2,1}, S_{2,2}, S_{3,1}, S_{6,3}$ & $\mathrm{~T} 2$ & $S_{1,1}, S_{2,1}, S_{2,2}, S_{3,1}, S_{6,3}$ \\
\hline & $\mathrm{T} 3$ & $S_{1,2}, S_{2,2}, S_{2,3}, S_{3,2}, S_{6,1}$ & $\mathrm{~T} 4$ & $S_{1,2}, S_{2,2}, S_{2,3}, S_{3,2}, S_{6,1}$ \\
\hline & T5 & $S_{1,3}, S_{2,1}, S_{2,3}, S_{3,3}, S_{6,2}$ & T6 & $S_{1,3}, S_{2,1}, S_{2,3}, S_{3,3}, S_{6,2}$ \\
\hline
\end{tabular}

Off $\cdots$ Other switches

where $\Delta q_{V_{i}}$ and $\Delta q_{V_{o 1}}$ are electric charges in $v_{i}$ and $v_{o 1}$, respectively. From Eqs.(1) (6), the following equation is derived:

$$
\overline{I_{i}}=\frac{3}{2} \overline{I_{o 1}} .
$$

In the converter block of Figure 4, the energy consumed by switches in one period, $W_{T}$, can be expressed as

$$
W_{T}=\sum_{t=T 1}^{T 6} W_{t}
$$

where

$$
W_{T 1}=\frac{4 R_{o n}}{T 1}\left(\Delta q_{T 1}^{1}\right)^{2}, W_{T 2}=\frac{3 R_{o n}}{T 2}\left(\Delta q_{T 2}^{1}\right)^{2},
$$

$$
W_{T 3}=\frac{4 R_{o n}}{T 3}\left(\Delta q_{T 3}^{2}\right)^{2}, W_{T 4}=\frac{3 R_{o n}}{T 4}\left(\Delta q_{T 4}^{2}\right)^{2},
$$

and $\quad W_{T 5}=\frac{4 R_{o n}}{T 5}\left(\Delta q_{T 5}^{3}\right)^{2}, W_{T 6}=\frac{3 R_{o n}}{T 6}\left(\Delta q_{T 6}^{3}\right)^{2}$.

In Eq.(8), the following equations are satisfied:

$$
\text { and } \quad \begin{aligned}
\Delta q_{T 1}^{1} & =\Delta q_{T 3}^{2}=\Delta q_{T 5}^{3} \\
\Delta q_{T 2}^{1} & =\Delta q_{T 4}^{2}=\Delta q_{T 6}^{3},
\end{aligned}
$$

because all the instantaneous equivalent circuits in phase $-T 1,-T 3,-T 5$ and phase $-T 2,-T 4,-T 6$ have the same structure. From Eqs.(1) (6) and (9), Eq.(8) can be rewritten as

$$
W_{T}=\frac{(16+11 D) R_{o n}}{9 D(1-D)} \cdot \frac{\left(\Delta q_{o 1}\right)^{2}}{T},
$$



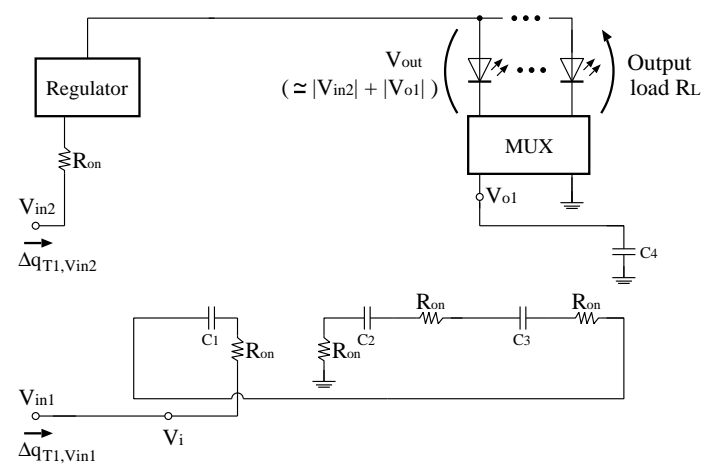

(a)
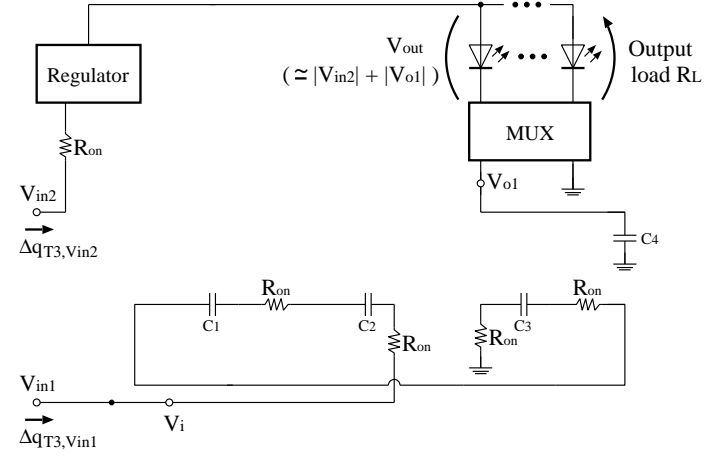

(c)

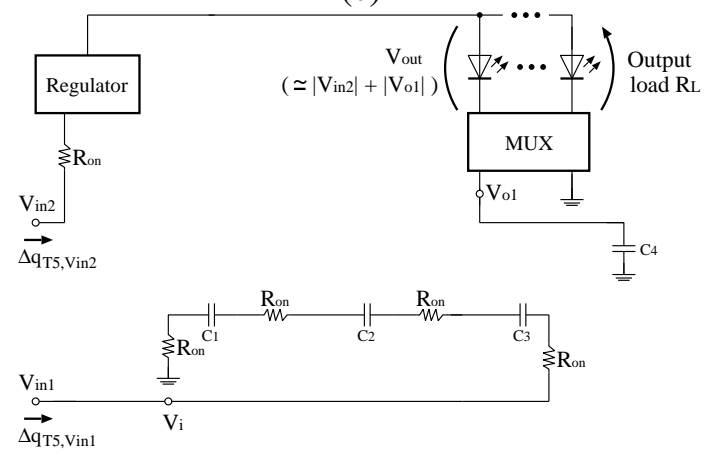

(e)

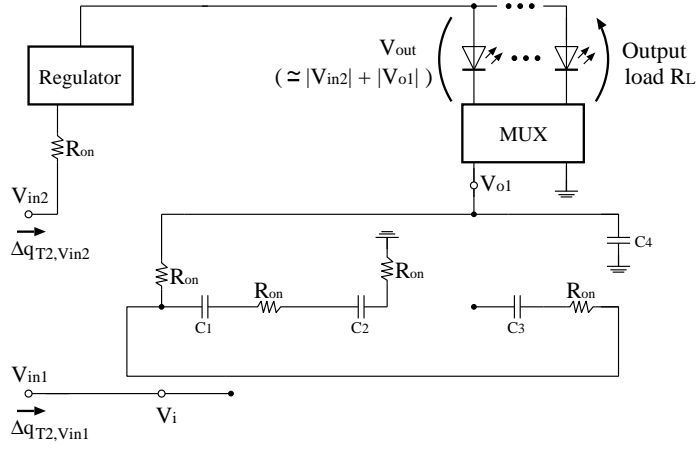

(b)

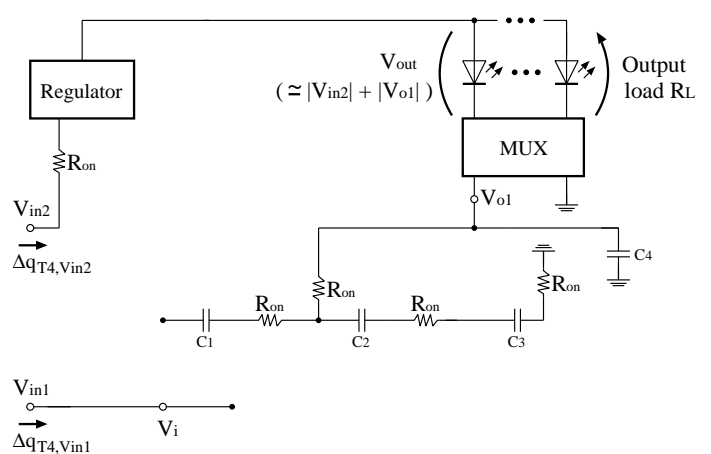

(d)

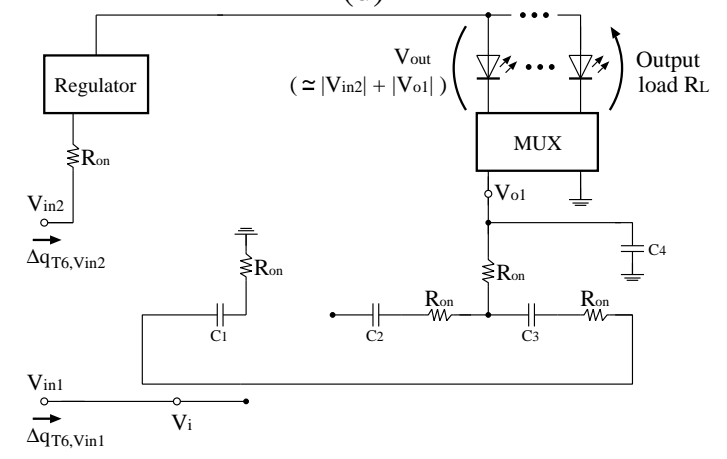

(f)

Figure 5 Instantaneous equivalent circuits in the case of Mode-3, (a) State - T1, (b) State - T2, (c) State - T3, (d) State - T4, (e) State - T5, (f) State - T6

where

$$
\begin{aligned}
T 1 & =T 3=T 5=D T \\
\text { and } \quad T 2 & =T 4=T 6=(1-D) T .
\end{aligned}
$$

Here, it is known that a general equivalent circuit of $\mathrm{SC}$ power converters can be expressed by the determinant using a Kettenmatrix [11]-[13]. In the general equivalent circuit of SC power converters, the consumed energy $W_{T}$ is defined as

$$
W_{T}:=\left(\frac{\Delta q_{V_{o 1}}}{T}\right)^{2} \cdot R_{S C} \cdot T
$$

where $R_{S C}$ is called the SC resistance. From Eqs.(10) and (12), $R_{S C}$ is given by

$$
R_{S C}=\frac{(16+11 D) R_{o n}}{9 D(1-D)} .
$$

Therefore, by using Eqs.(7) and (13), the equivalent circuit of the converter block is given by

$$
\left[\begin{array}{c}
\overline{V_{i}} \\
\overline{I_{i}}
\end{array}\right]=\left[\begin{array}{ll}
3 & 0 \\
2 & 2 \\
0 & \overline{3}
\end{array}\right]\left[\begin{array}{cc}
1 & R_{S C} \\
0 & 1
\end{array}\right]\left[\begin{array}{c}
-\overline{V_{o 1}} \\
\overline{I_{o 1}}
\end{array}\right] .
$$

From Eq.(14), the equivalent circuit of Figure 4 can be expressed by the circuit shown in Figure 6. In Figure 
Table 4 Summary of theoretical results

\begin{tabular}{|c|c|c|c|}
\hline Mode & Condition of $V_{i n 1}$ & Conversion ratio & $R_{S C}$ \\
\hline Mode-1 & $3\left(V_{t a g}-V_{i n 2}\right)<V_{i n 1}$ & $-\frac{1}{3} \times$ & $\frac{(4+14 D) R_{o n}}{9 D(1-D)}$ \\
\hline Mode-2 & $2\left(V_{t a g}-V_{i n 2}\right)<V_{i n 1} \leq 3\left(V_{t a g}-V_{i n 2}\right)$ & $-\frac{1}{2} \times$ & $\frac{(3+5 D) R_{o n}}{4 D(1-D)}$ \\
\hline Mode-3 & $\frac{3}{2}\left(V_{t a g}-V_{i n 2}\right)<V_{i n 1} \leq 2\left(V_{t a g}-V_{i n 2}\right)$ & $-\frac{2}{3} \times$ & $\frac{(16+11 D) R_{\text {on }}}{9 D(1-D)}$ \\
\hline Mode-4 & $V_{t a g}-V_{i n 2}<V_{i n 1} \leq \frac{3}{2}\left(V_{t a g}-V_{i n 2}\right)$ & $-1 \times$ & $\frac{2 R_{o n}}{D(1-D)}$ \\
\hline Mode-5 & $\frac{2}{3}\left(V_{t a g}-V_{i n 2}\right)<V_{i n 1} \leq V_{t a g}-V_{i n 2}$ & $-\frac{3}{2} \times$ & $\frac{(27-11 D) R_{o n}}{4 D(1-D)}$ \\
\hline Mode-6 & $\frac{1}{2}\left(V_{t a g}-V_{i n 2}\right)<V_{i n 1} \leq \frac{2}{3}\left(V_{t a g}-V_{i n 2}\right)$ & $-2 \times$ & $\frac{(8-5 D) R_{o n}}{D(1-D)}$ \\
\hline Mode-7 & $\frac{1}{3}\left(V_{t a g}-V_{i n 2}\right)<V_{i n 1} \leq \frac{1}{2}\left(V_{t a g}-V_{i n 2}\right)$ & $-3 \times$ & $\frac{(18-14 D) R_{o n}}{D(1-D)}$ \\
\hline Mode- 8 & $\frac{2}{3} V_{t a g}<V_{i n 1}$ & $\frac{3}{2} \times$ & $\frac{19 R_{\text {on }}}{4}$ \\
\hline Mode-9 & $\frac{1}{2} V_{t a g}<V_{i n 1} \leq \frac{2}{3} V_{t a g}$ & $2 \times$ & $7 R_{o n}$ \\
\hline Mode-10 & $\frac{1}{3} V_{t a g}<V_{i n 1} \leq \frac{1}{2} V_{t a g}$ & $3 \times$ & $16 R_{\text {on }}$ \\
\hline
\end{tabular}

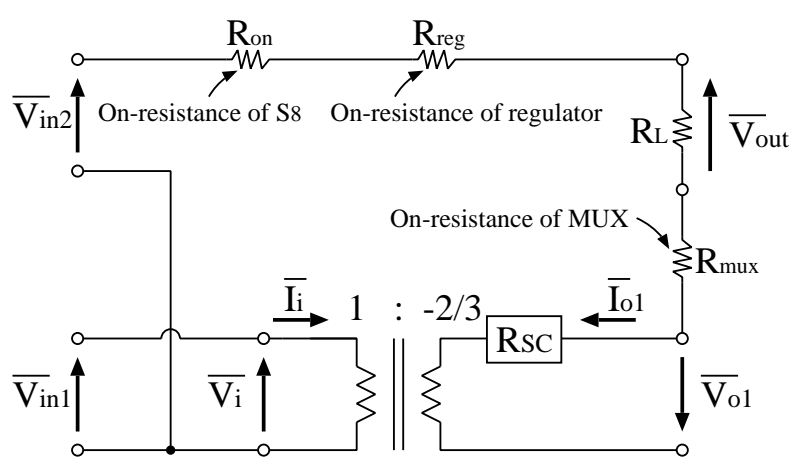

Figure 6 Equivalent circuit of the proposed driver in the case of Mode- 3

6, power efficiency $\eta^{3}$ and output voltage $\overline{V_{\text {out }}}$ are given by

$$
\eta=\frac{R_{L}}{R_{L}+R_{S C}+R_{o n}+R_{\text {mux }}+R_{\text {reg }}}
$$

and

$$
\begin{aligned}
& \overline{V_{\text {out }}}=\left(V_{\text {in } 2}+\frac{2}{3} V_{\text {in } 1}\right) \\
& \times \frac{R_{L}}{R_{L}+R_{S C}+R_{o n}+R_{\text {mux }}+R_{\text {reg }}} .
\end{aligned}
$$

\footnotetext{
${ }^{3}$ The consumed energy of peripheral circuits such as pulse generators, regulators, etc. is disregarded.
}

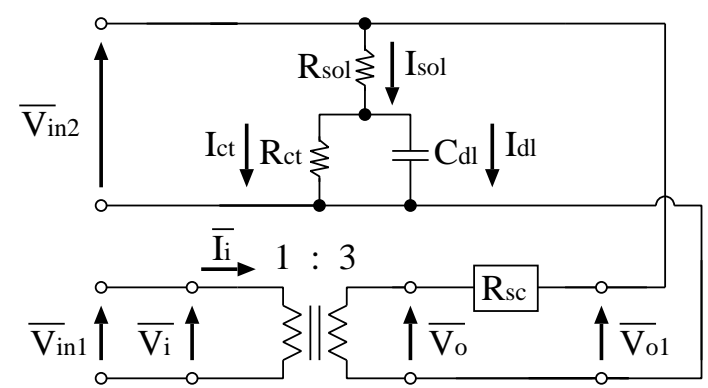

Figure 7 Equivalent circuit of the proposed driver in the case of Mode-3

To save space, the theoretical analysis of other conversion modes is omitted in this paper. However, other modes can also be analyzed by the same method. Table 4 shows the summary of the theoretical results.

\subsection{Analysis of Charge Process}

From the theoretical results shown in Table 4, the equivalent circuit in the case of Mode-10 can be expressed by Figure 7. In Figure 7, the rechargeable battery which is connected to terminal $V_{i n 2}$ is modeled by using $R_{s o l}, R_{c t}$ and $C_{d l}$, where $R_{s o l}, R_{c t}$ and $C_{d l}$ denote the solution resistance, the charge transfer resistance and the double layer capacitance, respectively. If the internal resistance of the lithium battery 
is small, the battery is charged by using voltage $V_{o}$ (see Figure 7). In Figure 7, the following equations are obtained:

$$
\begin{array}{ll} 
& V_{o}=\left(R_{s o l}+R_{S C}\right) \frac{d q_{s o l}}{d t}+\frac{q_{d l}}{C_{d l}}, \\
& I_{s o l}=I_{c t}+I_{d l} \\
\text { and } \quad & R_{c t} I_{c t}=\frac{q_{d l}}{C_{d l}},
\end{array}
$$

where $q_{s o l}, q_{c t}$ and $q_{d l}$ denote electric charges of $I_{s o l}$, $I_{c t}$ and $I_{d l}$, respectively. From Eq.(17), the following ordinary-differential-equation is derived:

$$
\begin{aligned}
V_{o}= & R_{\text {sum }} \frac{d q_{d l}}{d t}+\left(\frac{R_{c t}+R_{\text {sum }}}{R_{c t} C_{d l}}\right) q_{d l}, \\
\text { where } & R_{\text {sum }}=R_{\text {sol }}+R_{S C} .
\end{aligned}
$$

By solving Eq.(18), the voltage of capacitor $C_{d l}, V_{C d l}$, can be expressed as

$$
\begin{aligned}
V_{C d l}= & V_{o}\left(\frac{R_{c t}}{R_{c t}+R_{\text {sum }}}\right) \\
& \times\left[1-\exp \left\{-\left(\frac{R_{c t}+R_{\text {sum }}}{R_{\text {sum }} R_{c t} C_{d l}}\right) t\right\}\right] \\
+ & V_{\text {ini }} \exp \left\{-\left(\frac{R_{c t}+R_{\text {sum }}}{R_{\text {sum }} R_{c t} C_{d l}}\right) t\right\}
\end{aligned}
$$

where $V_{i n i}$ denotes the initial voltage of $C_{d l}$. Especially, if the initial electric charge of $C_{d l}$ is zero, Eq.(19) can be rewritten as

$$
\begin{aligned}
V_{C d l}= & V_{o}\left(\frac{R_{c t}}{R_{c t}+R_{\text {sum }}}\right) \\
& \times\left[1-\exp \left\{-\left(\frac{R_{c t}+R_{\text {sum }}}{R_{\text {sum }} R_{c t} C_{d l}}\right) t\right\}\right] .
\end{aligned}
$$

As Eqs.(19) and (20) show, the voltage of the lithium battery rises exponentially.

\section{Simulation}

To investigate properties of the proposed driver, SPICE simulations were performed concerning the circuit shown in Figure 4. Figure 8 shows the simulated power efficiency, where $C_{1}=\cdots=C_{4}=2 \mu \mathrm{F}, R_{o n}=$ $R_{\text {mux }}=R_{\text {reg }}=2 \Omega$ and $T=3 \mu$ s. In Figure 8 , power efficiency $\eta$ was calculated by $\eta=P_{\text {out }} /\left(P_{i n 1}+P_{i n 2}\right)$ , where $P_{\text {out }}$ is the output power, $P_{i n 1}$ and $P_{i n 2}$ are the input power for input $V_{i n 1}$ and $V_{i n 2}$, respectively. As Figure 8 shows, the theoretical results correspond well with SPICE simulated results. For this reason, the derived theoretical formulas will be helpful to design the hybrid-input negative ring-type converter.

Figure 9 shows the simulated output voltages in the case of Mode- $1 \sim-7$. As Figure 9 shows, in spite of

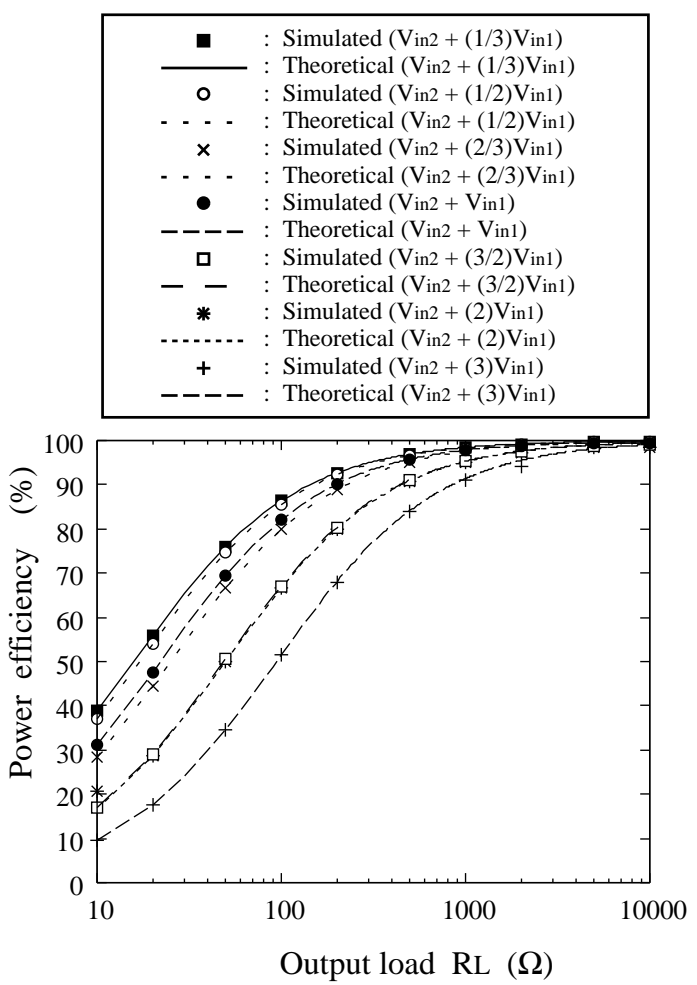

Figure 8 Simulated power efficiency as a function of output load $R_{L}$

variation in $V_{i n 1}$, the proposed driver can provide sufficient voltage to drive LEDs by utilizing the clean energy effectively. The converter block can realize not only step-down conversion but also step-up conversion.

Figure 10 shows the simulated charge process in the case of Mode-10. In SPICE simulations of Figure 10, the battery was modeled by using the equivalent circuit shown in Figure 7, where $R_{s o l}, R_{c t}$ and $C_{d l}$ were set to $R_{\text {sol }}=5 \Omega, R_{c t}=1 \mathrm{k} \Omega$ and $C_{d l}=50 \mu \mathrm{F}$, respectively. As Figure 10 shows, the proposed driver can provide the positive stepped-up voltage to charge the rechargeable battery. Consequently, the proposed driver achieves longer battery lifetime than conventional converters.

\section{Conclusion}

For back-lighting applications, a hybrid-input white LED (WLED) driver using a negative ring-type converter has been proposed in this paper. Through theoretical analyses and SPICE simulations, the properties of the proposed driver were investigated.

The SPICE simulations and theoretical analyses showed: 1. Unlike conventional drivers, the proposed driver can offer sufficient voltage to drive LEDs by using 


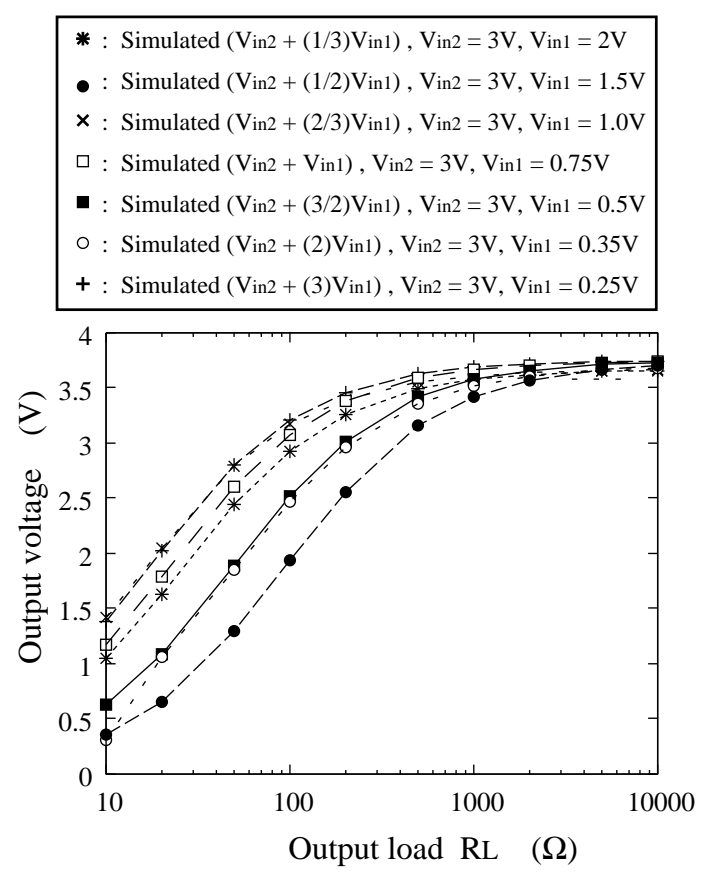

Figure 9 Simulated output voltage in the case of Mode-1 $-7$

not only battery energy but also clean energy, because the proposed driver can realize negative step-up/stepdown conversion. 2 . The proposed driver can realize long battery lifetime, because the battery-charge process was confirmed through SPICE simulations. 3. The formulas obtained by the theoretical analyses are useful for designing the proposed driver, because the theoretical results agreed well with the simulation results.

\section{References}

[1] J. A. Starzyk, T. W. Jan, and F. Qiu, "A DCDC charge pump design based on voltage doublers," IEEE Trans. Circuit \& Syst.-I, vol.48, no.3, 2001.

[2] C. L. Wei, L. Y. Wu, H. H. Yang, C. H. Tsai, B. D. Liu, and S. J. Chang, "A versatile stepup/step-down switched-capacitor-based DC-DC converter," IEICE Trans. Electronics, vol.E91C, no.5, pp.809-812, 2008.

[3] T. Tanzawa and T. Tanaka, "A dynamic analysis of the Dickson charge pump circuit," IEEE, Solid-State Circuits, vol.32, no.8, pp.1237-1240, 1997.

[4] K. Min and J. Ahn, "CMOS charge pumps using cross-coupled charge transfer switches with im-

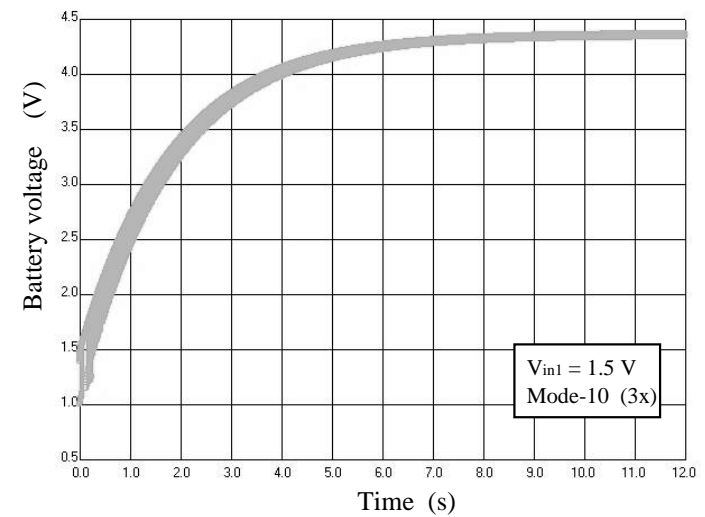

Figure 10 Simulated charge process in the case of Mode-10

proved voltage pumping gain and low gate-oxide stress for low-voltage memory circuits," IEICE, Electron., vol.E85-C, no.1, pp.225-229, 2002.

[5] I. Doms, P. Merken, C. V. Hoof and R. P. Mertens, "Capacitive power management circuit for micropower thermoelectric generators with a $1.4 \mu \mathrm{A}$ controller," IEEE, J. Solid-State Circuits, vol.44, no.10, pp.2824-2833, 2009.

[6] S. J. Park, Y. G. Kang, J. Y. Kim, T. H. Han, Y. H. Jun, C. Lee and B. S. Kong, "CMOS crosscoupled charge pump with improved latch-up immunity," IEICE Electronics EXpress, vol.6, no.11, pp.736-742, 2009.

[7] I. Y. Chung and J. Shin, "New charge pump circuits for high output voltage and large current drivability," IEICE Electronics EXpress, vol.6, no.12, pp.800-805, 2009.

[8] J. Kim, "Negative charge pumps achieve inductor-like efficiency for WLED backlights", MAXIM Engineering Journal, vol.64, pp.13-15, 2008.

[9] N. Hara, I. Oota, F. Ueno, and I. Harada, "A programmable ring type switched-capacitor AC-DC converter," Proc. of the International Symposium on Nonlinear Theory and its Applications, vol.1, pp.159-162, 1999.

[10] S. Terada, I. Oota, K. Eguchi, and F. Ueno, "A ring-type switched-capacitor (SC) programmable converter with $\mathrm{DC}$ or $\mathrm{AC}$ input/DC or AC output," Proc. of the 47th IEEE International Midwest Symposium on Circuits and Systems, vol.I, pp.29-32, 2004. 
[11] K. Eguchi, I. Oota, S. Terada, and T. Inoue, "A design method of switched-capacitor power converters by employing a ring-type power converter," Int. J. of Innovative Computing, Information and Control, vol.5, no.10(A), pp.29272938, 2009.

[12] K. Eguchi, S. Pongswatd, K. Tirasesth, H. Sasaki, and T. Inoue, "Optimal design of a single-input parallel DC-DC converter designed by switched capacitor techniques," Int. J. of Innovative Computing, Information and Control, vol.6, no.1(A), pp.215-227, 2010.

[13] K. Eguchi, I. Oota, S. Pongswatd, A. Julsereewong, K. Tirasesth, and H. Sasaki, "Synthesis and analysis of a dual-input parallel DC-DC converter designed by using switched capacitor techniques," Int. J. of Innovative Computing, Information and Control, vol.7, no.4, pp.16751688, 2011. 